\section{Active in reducing tension}

\section{Martin J. Schick}

Surfactants.

Edited by Th. F. Tadros. Academic: 1984. Pp.342. \$30, £20.

SURFACTANTS not only present intriguing problems of basic science to the physical chemist but are of widespread application in industry. The field is thriving, on both its "pure" and "applied" sides. To examine the current state of work in this area, a residential school - sponsored by the Royal Society of Chemistry and attended by a galaxy of experts - was held at Bristol University in 1983. This book contains the printed record of lectures presented at the meeting, and is divided into two unequal parts; ten chapters deal with the basic principles of the physical chemistry of surfactants and dispersed systems, while a final three cover applications.

The first four contributions provide a contemporary overview of the solution properties of surfactants, with accounts of the thermodynamics of surfactant solutions, phase equilibria and mesophases in surfactant systems, and the structural aspects of micellar systems. The last of these, by B. Lindman, is especially successful in making clear the importance of simple geometric features and electrostatic effects. New methods for the study of micellar systems, such as quasi-electric light scattering, multifield ${ }^{13} \mathrm{C}$ NMR chemical shift, multifield proton NMR and NMR water self-diffusion, are explained, and the timely subject of microemulsions is illustrated by J.T.G. Overbeek with phase diagrams, thermodynamics, techniques of characterization and applications. Also included are discussions of the microstructure and rheology of surfactants in dilute and concentrated systems, adsorption at the three interfaces (with explanations of experimental procedures), and the role of surfactants in controlling the stability of emulsions, foams and suspensions. This first part of the book concludes with an upto-date account of the fundamentals of wetting, incorporating a selective review of the recent literature.

Unfortunately, the last three contributions - on surfactants in enhanced oil recovery, macromolecular surfactants, and applications in biological systems do not measure up to the standard of the earlier part of the book. For example, the title "Macromolecular Surfactants" is grossly misleading since this chapter deals almost exclusively with non-ionic surfactants originating only from the author's own company. On p.287 the misprint of the formula of the alkylphenol ethoxylate is unfortunate and on p.305 the downgrading of the HLB system is not justified.
Yet the high quality of the first ten chapters more than compensates. The concise treatment and scholarly approach to be found there will make this volume useful to both the newcomer and the practitioner who wants to learn about the latest developments. Graduate and research chemists will benefit greatly from reading it. Still, I can't help but feel that omission of the applications chapters and a title such as Introduction to the Physical Chemistry of Surfactants would have meant an altogether more useful book.

Martin J. Schick is a consultant physical chemist based in New York and editor of the Surfactant Science series published by Marcel Dekker.

\section{Something cooking}

\section{G.D. Clarke}

Cell Culture Methods for Molecular and Cell Biology, Vols 1,2,3 and 4.

Edited by David W. Barnes, David A.

Sirbasku and Gordon H. Sato.

Alan R. Liss/Wiley: 1984. Vol. 1 pp.353,

$\$ 49.50$, £38. Vol. 2 pp.280, \$39.50,

f30. Vol. 3 pp.300, \$49.50, £38. Vol. 4

pp.263, \$39.50, £30.

THE science of making media for animal cell culture grew slowly out of the black arts of the bacteriologist's "kitchen" with its steamy atmosphere, arcane recipes and horny-handed aficionados. They knew nothing of the composition of their brew, merely that it worked. This art, even in its modern, scientific form is not an activity with appeal for all, yet scientists in the laboratories of such as Richard Ham and Gordon Sato - herein represented - have made contributions which show signs of increasing application, not only to pure scientific enquiry, but also to industrial and clinical practice. Their achievement is in devising serum-free media which do not merely grow aberrant cells selected in these media, but also cells from embryonic, adult and tumour tissues of many different types.

These are not books for every biologist or the common reader: Alan Freshney's recent Culture of Animal Cells from the same stable fulfils that role best. These are for the specialist and, in particular, for those who choose not to rely on commercial sources for the many growth factors which now take the place of serum. Much of the first volume concerns the history and philosophy of synthetic media and solid substrata, though it also contains details for the purification of the less esoteric growth factors (PDGF, MSA, EGF, type $\beta$-TGF, MDGF and ECGF). Others of more limited use are conveniently covered in the more specialized volumes: FGF in Vol. 3 (Epithelial Cells and Fibroblasts), interleukin-2, $\mathrm{T}$-cell growth factor and thymosins in Vol. 4

Advertisements

ANSWERS

to your questions about nuclear energy

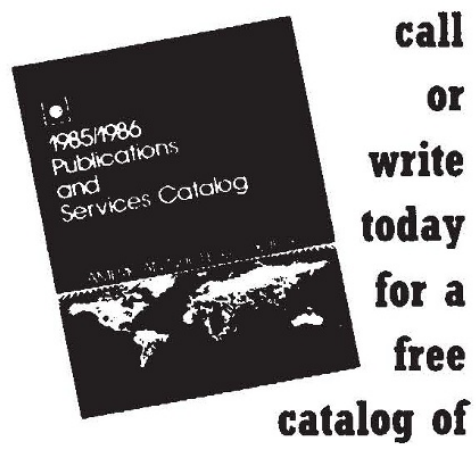

answers and facts about nuclear.

AMERICAN NUCLEAR SOCIETY 555 N. Kensington Ave. La Grange Park, IL 60525 (312) 352-6611

Circle No.07 on Reader Service Card.

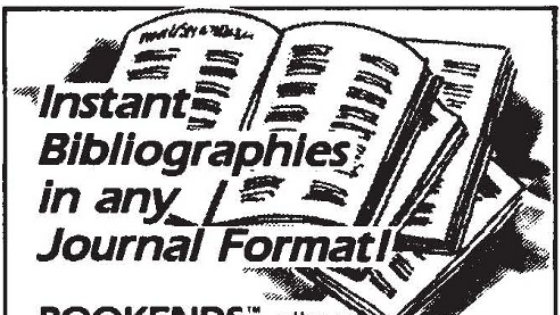

BOOKENDS

you to quickly put your finger on any journal, any paper, any book, any specific information contained in your voluminous files.

As the New England Journal of Medicine states in its issue of January 12, 1984, it "addresses two widespread problems: first, the challenge of cataloging all the information we read second...the need to convert bibliographic information into the...format demanded by each medical journal. Both problems are solved here in an excellent way."

Bookends has extraordinary versatility and edits with the ease of a word processor. There is no quicker or more efficient means of saving, retrieving and formatting reference information.

\section{BOOKENDS}

the reference management software system is available for Apple computers for \$124.95. Apple is a trademark of

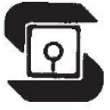
Sensible Software, Inc. ${ }^{(8)}$ 210 S. Woodward, Suite 229 Birmingham, MI 48011 (313) 258-5566

Circle No.04 on Reader Service Card. 